\title{
Importance of the chaetotaxy in larval identification of Galleria mellonella (Linnaeus) (Lepidoptera: Pyralidae) along with some notes on its life history
}

\author{
D. S. Deep ${ }^{1 *}$, H. S. Rose ${ }^{2}$ and P. C. Pathania ${ }^{3}$ \\ 'Department of Life Sciences, RIMT University, Mandi Gobindgarh - 147301, \\ Punjab, India; deepinderpal2002@yahoo.co.in \\ ${ }^{2}$ Department of Zoology and Environmental Sciences, Punjabi University, Patiala - 147002, Punjab, India \\ ${ }^{3}$ Zoological Survey of India, Kolkata - 700053, West Bengal, India
}

\begin{abstract}
Earlier studies on identification of Galleria mellonella emphasized mainly on characterization of wing venation and maculation, larval or pupal morphology and other taxonomic characters such as male and female genitalia. The larval identification and diagnostic characters of pest species can best be strengthen through diagnosis of the setal arrangement and position of punctures present of different larval body segments. The cephalic region and all the bodily segments such as thoracic, abdominal etc of the last instar larva of Greater waxmoth, Galleria mellonella (Linnaeus) belonging to family (Pyralidae) have been examined along with some biological aspects.
\end{abstract}

Keywords: Chaetotaxy, Lepidoptera, Pyralidae, Setae, Species, Stemmata

\section{Introduction}

Galleria mellonella (Linnaeus) belongs to subfamily Galleriinae (family Pyralidae) also known as greater wax moth. Earlier workers such as Fabricius and Walker classified this pest as G. cereana and G. obliquella respectively. The current nomenclature of this pest species was given by Linnaeus, who reclassified it as G. mellonella (Linnaeus). The larvae of G. mellonella Linnaeus make a tunnel into the periphery of unsealed cells of the bee species Apis mellifera Linnaeus and A. cerana Fabricius. Worldwide, a small group of workers such as Mathur (1954 and 1959), Mathur and Singh (1963), Azam and Ali (1965), Franzmann and Garrett (1978), Yoshiyasu (1980), Goel and Kumar (1981), Stehr (1987), Lin 1995, Amutha and David (1998), Rose and Singh (2010) and Pinheiro et. al., (2011) have attempted chaetotaxic studies of few species. Due to the paucity of proper information on this pest, the chaetotaxic and biological studies were initiated to identify this species at its imago stage.

\section{Material and Methods}

The caterpillars of this serious pest collected from the infested beehives and reared in the Lepidoptera laboratory for collecting further information on its life history. For chaetotaxic studies, the last larval instar body was first distended by boiling it in the test tube which then spread on a glass slide by giving a long ventral cut with a surgical blade. For proper maceration, cephalic region and the remaining body were kept in $10 \% \mathrm{KOH}$ separately followed by wash in $1 \%$ glacial acetic acid and then preserved in 70\% alcohol and glycerin in the ration of 9:1 for further studies (Stehr, 1987). To study setal arrangement, larval heads shifted to watch glass containing glycerin whereas permanent slides of thorax

\section{*Author for correspondence}


and abdomen were made by fixing them in DPX on glass slide and then observed under stereoscopic zoom microscope.

\section{Results}

Cephalic chaetotaxy: (Plate-2, Figure 1 and 2): Generally each half of head contains different types of setae in varied numbers from which 17 tactile setae, 4 proprioceptors and 10 pores; All the spine like setae originate from pinacula. Cranium strongly sclerotized and light dirty brown with median epicranial suture very reduced; frontoclypeus longer than broad, stemmatal area not well differentiated from rest of cranium but contains six stemmata, fifth stemmata placed at base of antenna and sixth behind fourth stemmata.

Seta F1 and pore Fa form frontal group; F1 closer to lateral margin of frons and postrad to $\mathrm{C} 1$; pore $\mathrm{Fa}$ lies near median longitudinal line of the head capsule, present anterodorsad to F1. Setae C1 and C2 comprises clypeal group; C2 close to epicondyle. C1 near median longitudinal line, longer than $\mathrm{C} 2$. Adfrontal goup contains setae AF1 and AF2 along with pore AFa; $\mathrm{AF} 2$ shorter than AF1; pore AFa much closer to AF2 than AF1 and anterolatrad to AF2. Setae A1, A2, A3 and pore Aa constitute anterior group; A1 anterodorsad to A2, lies towards median longitudinal line; A3 posterolaterad to $\mathrm{A} 2$; $\mathrm{A} 1>\mathrm{A} 3>\mathrm{A} 2$ lengthwise; pore Aa lies close to $\mathrm{A} 2$ than A1. Posterodorsal group beset with setae $\mathrm{P} 1$ and $\mathrm{P} 2$ along with pore $\mathrm{Pb}$; $\mathrm{P} 1$ much longer than $\mathrm{P} 2$; $\mathrm{P} 2$ posteromesad to $\mathrm{P} 1$; pore $\mathrm{Pb}$ anterad to $\mathrm{P} 2$. Seta $\mathrm{L} 1$ and pore La decorates lateral group; L1 directly dorsad to stemmata 1, pore La posteromesad to L1. Stemmatal area comprises setae S1, S2, and S3 besides pore Sa and Sb; S1 situated inside stemmatal semicircle, close but ventrocaudad to stemmata 2; S2 ventrocaudad to stemmata 1, present at mouth of stemmatal arc, S3 posterad to stemmata 6; $\mathrm{S} 1>\mathrm{S} 2=\mathrm{S} 3$ lengthwise; pore Sa situated caudad to stemmata 6; pore Sb lies very close and infront of stemmata 4 . Setae SS1, SS2 and SS3 with pore SSa furnish the substemmatal area; SS1 lies directly below stemmata 5; SS2 lies caudad to stemmata 5; SS3 ventrocaudad to SS2; $S S 3=S S 2>S S 1$ lengthwise. MG1 and pore MGa decorates the genal group; MG1 lies at lower and rear portion of the head; pore MGa lies posterodorsad to MG1. Dorsal epicranial area contains proprioceptor setae MD1, MD2, MD3 and pore MDa.; MD1 posterolatrad to P2; MD2 posterolatrad to MD1; MD3 posterad to MD1; Pore MDa present much closer to MD2 than MD3.

Thoracic chaetotaxy: (Plate-2, Figure 3 and 4) Spine like setae but tactile in nature

T1: Prothoracic shield golden brown; elongated; strongly sclerotized; anterior margin with rounded edges. Each half contains six setae and two pores. XD group present near anterior margin of the shield; XD1 dorsad to XD2; pore $\mathrm{XDa}$ anterad to $\mathrm{XD1}$; pore $\mathrm{XDb}$ posterodorsad to $\mathrm{XD} 2$. Setae D1 and D2 make the dorsal group; seta D1 lies posterodorsad to XD1 near distal margin of the shield; seta D1 lies posterolatrad to D1; D2 longer than D1. Subdorsal group present on lateral margin of the shield; SD1 close and posterolatrad to seta XD2; SD1 longer than SD2, the latter lies posterodorsad to SD1. Lateral group bisetose with setae L1 and L2 present on same prespiracular pinaculum; L2 longer than L1; the latter posterolatrad to SD1; L2 anterad to L1. Subventral group lies above the leg base, bisetose and situated on a common large pinaculum; SV2 anterodorsad to the seta SV1; seta SV1 longer than SV2 in length. Micro seta MXD1 present at equal distant from setae D1 and D2 towards the posterior side of the segment; Microventral group absent. Ventral group contains single tactile seta V1 and present below the coxa.

T2 and T3: Dorsal group furnished with two setae D1 and D2 present on separate pinacula; D1 dorsad to D2; latter longer than D1. Subdorsal group bisetose furnished with setae SD1 and SD2 lying on separate pinacula SD2 anterolatrad to D2; SD1 anterolatrad to SD2; SD1 longer than SD2. Lateral group trisetose, with setae L1, L2 and L3 present on separate pinacula; seta L1 and L2 closer to each other; seta L3 present away from L1 and L2; L1 anteroventrad to SD1; L2 anteroventrad to L1 L3 posterad to L1. Sudventral group bisetose containing setae SV1 and SV2, lying on common somewhat oval pinaculum; SV1 posterodorsad to SV2. Ventral group unisetose and present below the coxa near the midventral line. Microsetae MD1, MSD1, MSD2 and microventral setae MV1, MV2 and MV3 present; MD1 anterolatrad to D2; MSD1 and MSD2 situated anterad to SD1; MSD2 anterolatrad to MSD2; seta MV1, MV2 and MV3 lying precoxal in position; MV2posteroventrad to MV1; MV3 posteroventrad to MV2. 


\section{Abdominal chaetotaxy: (Plate-2, Figure 5,6,7,8 and 9)}

A1, A2, A7 and A8: Dorsal group present near middorsal line and furnished with setae D1 and D2; seta D1 anterodorsad to D2; the latter longer than D1 in segments $\mathrm{A} 1$ and A2, but smaller than D1 in segments A7 and A8. Subdorsal group comprises setae SD1 and SD2; seta SD1 present just above the spiracle; seta SD2 minute, present anterad to SD1. Lateral group trisetose with setae L1, L2 and L3; setae L1 and L2 lying close to each on same pinaculum; L3 present away on separate pinaculum; L1 ventrad to spiracle; L2 anterodorsad to L1; L3 posteroventrad to L1; L3 $>$ L1 $>$ L2 lengthwise. In segment $\mathrm{A} 1$ and $\mathrm{A} 2$, subventral group trisetose containing seta SV1, SV2 and SV3; SV3 much longer than SV2 and SV1; seta SV1 and SV2 close to each other; SV3 ventrad to SV2; SV1 anteroventrad to L3; SV2 ventrad to SV1. In segment A7 and A8, SV group bisetose, SV2 anteroventrad to SV1. Ventral seta V1 present towards ventral meson. Microsetal group MD and MV present; seta MD1 lies anterolaterad to D1; in segments A1 and A2, seta MV3 lies towards the anterior margin of the segment and anterad to seta SV3; in segments A7 and A8, MV3 anterad to SV2.

A3, A4, A5 and A6: Prolegs present on all these four segments. Setae D1 and D2 constitute dorsal group; D1 dorsad to spiracle, present near middorsal line; D2 posterolatrad to D1; D2 longer than D1 in length. Subdorsal group bisetose beset with setae SD1 and SD2; SD1 situated above the spiracle and almost latrad to D1; SD2 microseta, present anterolatrad to spiracle. Lateral group trisetose having setae L1, L2 and L3; setae L1 and L2 present on same pinaculum; L3 present on different small rounded pinaculum; the pinaculum of L1 and L2 present ventrad to spiracle; L2 dorsoanterad to L1; L3 posteroventrad to L1; L1>L3>L2 legthwise. Subventral group trisetose beset with setae SV1, SV2 and SV3 on common pinaculum, lying in dorsal area of proleg; SV1 anteroventrad to L3; SV2 anterodorsad to SV1; SV3 anteroventrad to SV2. V1 seta of ventral group present towards ventral meson. Microsetae MD1 and MV1 present; Microsetae looks prominent and larger than other group of setae. MD1 anterolaterad to D1; MV3 precoxal in position. Crochets biordinal.
A9: group bisetose having setae D1 and D2; D2 present close to middorsal line and posterodorsad to D1. D2 larger than D1. Subdorsal group unisetose having seta SD1 posterolatrad to D1. Lateral group trisetose beset with setae L1, L2 and L3; L1 and L2 setae present close to each other than L3; L3 longer in length than L1; L1 longer than L2; L1 posteroventrad to L2; L3 posteroventrad to L1. Subventral group unisetose beset with setae SV1, posteroventrad to L3. V1 seta of ventral group present towards ventral meson. Microdorsal seta MD1 present, anterodorsad to D1. Microventral seta MV3 seems to be absent.

A10: Anal shield well developed oblong; seta D1 present near anterior margin of the shield; D2 longer in length than D1; D2 lies at distal margin of the shield. SD1 anteroventrad to D2; SD2 present near lateral margin of the shield; SD2 anteroventrad to SD1; SD1 longer than SD2. Lateral group present at lateral margin of the anal leg with seta L1 present interiorly; L3 posterodorsad to L1; L2 anteroventrad to L3. Subventral group composed of setae SV1, SV2, SV3 and SV4; seta SV1 anteroventrad to L3; SV2 posterocaudad to SV3; seta SV1 and SV3 almost in straight line, SV3 ventrad to SV1. V1 seta of ventral group present towards ventral meson and slightly but ventrad to seta SV4.

\section{Life history: (Plate-1, Figure 1, 2, 3 and 4)}

Being the element of family Pyralidae, Galleria mellonella, is universally known as the greater wax moth. As the name indicates, it infests the honey bee hive by burrowing into the frame of the unsealed cells which causes Galriasis during the course of present studies; the various life history aspects have been studied very precisely to strengthen the information of this pest.

The eggs are dirty white in colour, ovoid and smooth, laid in crevices of bee hive in clusters of 50 100.The first instar larvae thus hatched out of egg shell passes through a total of seven larval instars to become prepupal/mature larva. To control this pest at an appropriate time, all the most concerned and important information like physical dimensions and time taken by the caterpillar up to maturity is given in the tabulate form below. 
Table 1. Physical dimensions of juvenile stages of Galleria mellonella (Linnaeus) $(\mathrm{N}=5$, Mean+S.D. in $\mathrm{mm})$

\begin{tabular}{|c|c|}
\hline Egg & \\
\hline Length & $0.38+0.02$ \\
\hline Width & $0.30+0.01$ \\
\hline First instar & \\
\hline Head width & $0.24+0.05$ \\
\hline Body length & $1.08+0.08$ \\
\hline Body Width & $0.35+0.02$ \\
\hline Second instar & $0.45+0.04$ \\
\hline Head width & $4.11+0.10$ \\
\hline Body length & $0.45+0.03$ \\
\hline Body Width & \\
\hline Third instar & $0.57+0.03$ \\
\hline Head width & $6.83+1.04$ \\
\hline Body length & $1.04+0.33$ \\
\hline Body Width & \\
\hline Fourth instar & $0.85+0.23$ \\
\hline Head width & $9.50+0.07$ \\
\hline Body length & $1.13+0.05$ \\
\hline Body Width & \\
\hline Fifth instar & $1.35+0.07$ \\
\hline Head width & $1.05+0.07$ \\
\hline Body length & $12.00+1.00$ \\
\hline Body Width & \\
\hline Sixth instar & \\
\hline Head width & \\
\hline Body length & \\
\hline Body Width & \\
\hline Seventh instar & \\
\hline Head width & \\
\hline Body length & \\
\hline Body Width & \\
\hline Pupa & \\
\hline Length & \\
\hline Width & \\
\hline
\end{tabular}

Table 2. Time duration of juvenile stages of Galleria mellonella (Linnaeus) (in days)

\begin{tabular}{|l|c|}
\hline Incubation period & $9.50+1.75$ \\
\hline First instar & $2.75+0.70$ \\
\hline Second instar & $3.00+0.18$ \\
\hline Third instar & $3.00+0.18$ \\
\hline Fourth instar & $3.25+0.70$ \\
\hline Fifth instar & $6.25+1.75$ \\
\hline Sixth instar & $4.00+1.25$ \\
\hline Seventh instar & $2.25+0.15$ \\
\hline Larval duration & $24.25+3.81$ \\
\hline Pupal duration & $6.75+1.25$ \\
\hline
\end{tabular}

\begin{tabular}{|l|c|}
\hline Generation time & $40.50+6.81$ \\
\hline Adult longevity & $9.25+2.75$ \\
\hline
\end{tabular}

\section{Adult Description}

Frons and vertex ochreous; antennae simple, light brown; forewing with costa straight, apex rounded, outer margin convex, tornus rounded, anal margin almost straight, concave near base, ground colour ochreous; hindwing with ground colour white ochreous, costa straight, apex rounded, outer margin concave, tornus rounded, anal margin straight, cilia white; abdomen pale yellow; legs covered with white scales.

\section{Discussion}

With regard to head, the frontal group in the order Lepidoptera is represented by a single seta $\mathrm{F} 1$ and a pore $\mathrm{Fa}$ (Heinrich, 1916). The similar condition in various taxa referable to Pyralidae (Azam and Ali, 1965; Doerksen and Neunzig, 1975; Yoshiyasu, 1980; Center et al., 1982; Franzmann and Garret, 1978; Yoshiyasu and Ohara, 1982; Rose and Behl, 1985; Passoa and Habeck, 1987); Noctuidae (Sohi and Mavi, 1969; Rishi, 1971; Psychidae (Davis, 2000); Crambidae (Solis, et.al. 2005) has been reported by the respective workers. The chaetotaxic investigation of Galleria mellonella (Linnaeus) conforms to these aforesaid studies. The two clypeal setae, $\mathrm{C} 1$ and C2 has been found to be present while dealing with different groups like Pyralidae (Mathur, 1954, 1959; Bhattacharjee and Menon, 1962; Mathur and Singh, 1956; Doerksen and Neunzig, 1975; Franzmann and Garrett, 1978; Yoshiyasu, 1980; Center et al., 1982; Yoshiyasu and Ohara, 1982; Rose and Behl, 1985; Passoa and Habeck, 1987; Amutha and David, 1998); Noctuidae (Sohi and Mavi, 1969; Rishi, 1971; Godfrey, 1973; Crambidae (Solis et al., 2005), by the respective workers. The similar condition of clypeal group (i.e., C1 and C2) has been seen in species under consideration. The adfrontal group possesses two setae i.e., $\mathrm{AF} 1, \mathrm{AF} 2$ and one pore i.e., $\mathrm{AFa}$ in the presently studied species i.e., G. mellonela (Linnaeus). A similar situation has been noticed by workers such as Bhattacharjee and Menon (1962); Azam and Ali (1965); Doerksen and Neunzig (1975); Franzmann and Garrett (1978); Center et al. (1982); Yoshiyasu and Ohara (1982); Rose and Behl (1985); Amutha and David (1998) in Pyralidae; Sohi and Mavi (1969); Rishi (1971); Godfrey 
(1973); Ogunwolu and Habeck (1979); Singh and Goel (1986); Neil and Specht (1987); Nasu and Komai (1997) in Noctuidae. In a Pyraloid species, studiedpresently, the anterior group comprises three setae i.e., A1, A2 and $\mathrm{A} 3 \mathrm{and}$ a pore $\mathrm{Aa}$ and the same has earlier been reported in the family viz., Pyralidae by Azam and Ali (1965); Doerksen and Neunzig (1975); Franzmann and Garrett (1978); Rose and Behl (1985) and Amutha and David (1998). In G. mellonella (Linnaeus), it has been observed that though both the setae $\mathrm{P} 1$ and $\mathrm{P} 2$ and pore $\mathrm{Pb}$ are present, yet the pore Pa may be absent. The absence of the pore $\mathrm{Pa}$ in a Tortricid species i.e., Tracholena homopolia (Turner) has earlier been recorded by Common (1973). Seta L1 of the lateral group is found to be present in G. melonella (Linnaeus). However, the occurrence of the pore La has been found to be variable. An absence of the pore in Esakiopteryx volitans (Butler), Trichopteryx misera (Butler), Trichopterigia costipunctaria Leech, Heterophleps fusca (Butler), Episteira nigrilinearia nigrilinearia (Leech) and Carige scutilimbata Prout of the family Geometridae has also been noticed by Hashimoto (1982, 1986, 1991, 1991a). The dorsal group on the caterpillar head contains three microsetae i.e., MD1, MD2 and MD3 and a pore MDa (Hinton, 1946), which are duly present in the species G. mellonella (Linnaeus). In Tortricid species such as Tracholena homopolia (Turner) (Common, 1973), Neobarbara olivacea Liu and Nasu, Epinotia tianshanensis Liu and Nasu and Zeiraphera gansuensis Liu and Nasu (Liu and Nasu, 1993, 1993a), the presence of the pore MDa has been noticed by the respective workers. The stemmatal group consists of three setae viz., S1, S2 and S3 and two pores $\mathrm{Sa}$ and $\mathrm{Sb}$ as has been observed in G. mellonella (Linnaeus). Darling (2003) has noted and confirmed the presence of three setae (S1, S2 and S3) and two pores Sa and $\mathrm{Sb}$ in the species Calindoea trifascialis referable to the family Thyrididae. Solis et al. (2005) have also noticed the presence of all the three setae and two pores in a species Albusambia elaphoglossumae Solis and Davis belonging to the family Crambidae. The substemmatal group containing three setae viz., SS1, SS2, SS3 and a pore SSa is duly represented in species under consideration. Workers like (Heinrich, 1916; Hinton, 1946; Stehr, 1987; Doerksen and Neunzig, 1975; Ogunwolu, 1978; Yoshiyasu, 1980; Hashimoto, 1982, 1986, 1991, 1991a; Nasu and Komai, 1997; Darling, 2003 and Solis et al., 2005) have also reported the same group.
In presently studied species Galleria mellonella (Linnaeus), all the six groups of tactile setae viz., XD, dorsal, subdorsal, lateral, subventral and ventral and two groups of proprioceptors i.e., MXD and MV have been duly seen on the T1 and prothoracic shield. The species i.e., Aenetus virescens (Butler), Agrotis ypsilon Rottemberg, Otoplecta frigida (Butler), Cochylis arthuri Dang, Heleanna melanomocla (Boisduval) and Calindoea trifascialis Moore have confirmed the status of two setae, yet there are two pores as has been reported by Grehan (1981), Rishi (1971), Hashimoto (1985), Darling (2003), Nasu (1995), Arthur and Powell (1990) respectively. The dorsal group is represented by two setae i.e., D1 and D2 which are duly present in G. mellonella (Linnaeus). The said position has earlier been reported in species such as Arotis flammarata Schiffermüllar (Sohi and Mavi, 1969), Agrotis ypsilon Rottemberg (Rishi, 1971), Chalciope hyppasis (Cramer) (Singh and Goel, 1986), Noctua pronuba (Linnaeus) (Neil and Specht, 1987) (Noctuidae), by the respective workers. During the course of present studies, it has been observed that the subdorsal group is bisetose and represented by two setae i.e., SD1 and SD2 which are always present in the G. mellonella (Linnaeus). Workers such as Sohi and Mavi (1969), Rishi (1971), Singh and Goel (1986) and Neil and Specht (1987) have reported similar setal arrangement in the species viz., Agrotis flammarata Schiffermullar, Agrotis ypsilon Rottemberg, Chalciope hyppasis (Cramer) and Noctua pronuba (Linnaeus) of family Noctuidae.

The lateral group on $\mathrm{T} 1$ is bisetose having setae i.e., L1 and L2 being present on a single pinaculum has been observed in the Pyraloid species i.e., Galleria mellonella (Linnaeus).The presence of two setae in the species of genus Plusia Felder, in species Hyblaea puera Cramer, Melanolophia imitata (Walker), Dichocrocis punctiferalis Guenée, Agrotis flammatra Schiffermüllar, Agrotis ypsilon Rottemberg, Nomophila noctuella Denis and Schiffermüller, Enargia decolor (Walker), Zophodia convolutella (Hübner) and Hellula rogatalis (Hulst) have also been recorded by workers such as Mukherji and Singh (1951); Singh (1955), Evans (1962), Azam and Ali (1965), Sohi and Mavi (1969), Rishi (1971), Mackay (1972), Wong and Melvin (1976) and Allyson (1980, 1981). The subventral group furnished with two setae i.e., SV1 and SV2 are always arranged on a common pinaculum in the species examined presently. An 
occurrence of two subventral setae in the species Hyblaea puera Cramer of family Hyblaeidaehas been reported by Singh (1955). The species G.mellonella (Linnaeus) reveals the occurrence dorsal (D1, D2) and Subdorsal (SD1, SD2) groups having bisetose present on the same pinaculumon segments T2 and T3. The similar condition have also been reported in certain moth species by the following workers (Singh, 1955; Mackay, 1959; Bhattacharjee and Menon, 1962; Azam and Ali, 1965; Evans, 1962; Sohi and Mavi, 1969; Rishi, 1971; Mackay, 1972; Common, 1973; Valley and Wheeler, 1976; Allyson ,1977, 1980, 1981, 1981a; Adamski and Brown, 1987; Komai and Ishikawa, 1987; Neil and Specht, 1987; Leonard et al., 1992; Liu and Nasu, 1993, 1993a; Nasu et al., 1993).

Due to variability in number,the setae of lateral group may be furnished by one seta i.e., L1 (Aenetus virescens Doubleday, Grehan, 1981), (Korscheltellus gracilis (Grote) and Sthenopis auratus (Grote), Leonard et al., 1992) or two setae viz., L1 and L2 (in genus Glyphidocera Walsingham, Adamski and Brown, 1987) or three setae viz., L1, L2 and L3 (Tracholena homopolia (Turner), Common, 1973), (Heleanna melanomocla (Meyrick), (Nomophila noctuella (Denis and Schiffermüller), Mackay, 1972), (Zophodia convolutella Hübner and Hellula rogatalis (Hulst), Allyson, 1980, 1981), (Melanolophia imitata (Walker), Evans, 1962), (Enargia decolor (Walker), Wong and Melvin, 1976), (Chalciope hyppasia (Cramer), Singh and Goel, 1986). In the present observations, the lateral group is always furnished by three setae i.e., L1, L2 and L3 in all the species studied presently. The subventral group may be having two setae i.e., SV1 and SV2 as in G. mellonella (Linnaeus). While, Zolotuhin (1994), Stehr (1987), Joshi et al. (1989) and Darling (2003) have observed that there are two setae SV1 and SV2 in the families Notodontidae, Sphingidae, Epiplemidae and Thyrididae respectively.

The dorsal group comprises two setae i.e., D1 and D2 which are present on A1-A8 in the present species have also the same arrangement as has been reported by Singh (1955) in the species Hyblaea puera Cramer of family Hyblaeidae; Evans (1962) in Melanolophia imitata (Walker) of family Geometridae; (Sohi and Mavi, 1969; Rishi, 1971; Wong and Melvin, 1976; Singh and Goel, 1986; Neil and Specht 1987; Singh and Goel, 1990) in species Agrotis flammarata Schiffermüllar, Agrotis ypsilon Rottemberg, Enargia decolor (Walker), Chalciope hyppasia (Cramer), Noctua pronuba (Linnaeus), Amyna leucostriga Hampson of family Noctuidaewhile working on different moth species. The subdorsal group having two setae i.e., SD1 and SD2 on A1-A8 has also been observed in the species under consideration. The presence of two subdorsal setae i.e., SD1 and SD2 (microscopic) on A1-A8 in species such as Stomopteryx palpilineella (Chambers) (Valley and Wheeler, 1976); Aproaerema karvoneni (Hackman) (Itämies and Kyrki, 1983); Tracholena homopolia (Turner) (Common, 1973); Statherotis discana (Felder et Rogenhofer) (Nasu et al., 1993); Heleanna melanomocla (Meyrick) (Nasu, 1995), (in certain species of genus Anthophila Haworth and Eutromula Froelich) (Arita and Diakonoff, 1979); Coryphista meadi atlantica Murnoe (Mackay, 1972); Zophodia convolutella (Hübner) and Hellula rogatalis (Hulst) (Allyson, 1980, 1981) of the families viz., Gelechiidae, Tortricidae, Choreutidae and Pyralidae have been reported by the respective workers.

Lateral group is trisetose having three setae i.e., L1, L2 and L3 on the abdominal segments in the Galleria mellonella (Linnaeus) which has also been observed in species Stomopteryxpalpilineella (Chambers), Aproaerema karvoneni (Hackman), Tracholena homopolia (Turner), Statherotis discana (Felder et Rogenhofer), Heleanna melanomocla (Meyrick), (in certain species of genus Anthophila Haworth and Eutromula Froelich), Coryphista meadi atlantica Murnoe, Zophodia convolutella (Hübner) andHellula rogatalis (Hulst)by Valley and Wheeler (1976), Itämies and Kyrki (1983),Common (1973), Nasu et al. (1993), Nasu (1995), Arita and Diakonoff (1979), Mackay (1972), Allyson (1980, 1981), in the respective publications. During present investigation, it has been found the presence of three setae SV1, SV2 and SV3 on A1 in G. mellonella (Linnaeus). Yen et al. (2004) recorded similar condition of three subventral setae in a new genus Austromusotima Yen and Solis in the family Crambidae.

In segment A2, trisetosed subventral group having setae SV1, SV2 and SV3, present in the Galleria mellonella(Linnaeus). Likewise Arita and Diakonoff (1979) have reported similar arrangement in the species Anthophila fabriciana Linnaeus and Eutromula vinosa discolor subsp. nov. of the family Choreutidae. In the presently studied species such as G. mellonella (Linnaeus), the subventral group is bisetose (i.e., SV1 and SV2) on A7. Similar bisetose arrangement on A7 has been found in species in Nomophila noctuella Denis and Schiffermüller (Pyralidae) (Mackay, 1972), in species of the genus Cryptoblabes (Pyralidae) (Yoshiyasu and Ohara, 1982), in Sceliodes laisalis Walker (Pyralidae) (Ogunwolu, 1978), 
in Smaneodes albigutalis (Warren) (Pyralidae) (Center et al., 1982), by the respective workers. Subventral group comprises two setae i.e., SV1 and SV2 on A8 in the species Galleria mellonella (Linnaeus). Many workers referable to the species such as Tracholena homopolia (Turner) (Common, 1973), Epiphyas postvittana (Walker) (Horak, 1991), Neobarbara olivacea Liu and Nasu (Liu and Nasu, 1993, 1993a), Epinotia tianshanesis Liu and Nasu, Zeiraphera gansuensis Liu and Nasu, Heleanna melanomochla (Meyrick) (Nasu, 1995) and Hendecaneura rhododendrophaga Nasu et Komai (Nasu and Komai, 1997) in family Tortricidae; Cryptoblabes aphidivora sp. nov. in Pyralidae (Yoshiyasu and Ohara, 1982) found the analogous arrangement.

The three setae i.e., SV1, SV2 and SV3 on each proleg bearing segment A3-A6 are present in the species Galleria mellonella (Linnaeus) of the superfamily Pyraloidea. This arrangement is in accordance with the works by Ogunwolu (1978), Brown and Nishida (2003), Darling (2004), Yen et al., (2004) and Solis et al. (2005) in the family Pyralidae, Tortricidae, Thyrididae and Crambidae. The presence of single seta $\mathrm{V} 1$ of the ventral group on A1A8in the species under consideration goes in accordance to the earlier works by Singh (1955), Evans (1962), Sohi and Mavi (1969), Rishi (1971), Mackay (1972), Common (1973), Wong and Melvin (1976), Allyson (1977, 1977a, 1980, 1981, 1981a), Arthur and Powell (1990), Leonard et al. (1992), Liu and Nasu (1993, 1993a), Nasu et al. (1993), Nasu (1995), Amutha and David (1998), Komai (1999).

On A9, the lateral group may be represented by three setae L1, L2 and L3 in Galleria mellonella (Linnaeus) which goes in accordance to earlier works by (Common, 1973; Allyson, 1977, 1977a, 1980; Wong et al., 1983; Arita, 1989; Horak, 1991; Nasu et al., 1993; Nasu, 1995; Nasu and Komai, 1997). The subventral group contains two setae i.e., SV1 and SV2 on A9 in the species, studied presently. On the basis of the present studies of $G$. mellonella (Linnaeus), it has been observed that on A10 segment, the lateral group is represented by three setae i.e., L1, L2 and L3. The subventral group may possess four setae i.e., SV1, SV2, SV3 and SV4 in G. mellonella (Linnaeus).

\section{Acknowledgements}

The authors are thankful to Ministry of Environment and Forests, New Delhi for providing funds to carry out the research work.

Abbreviations: A - Anterior seta; AF - Adfronal seta; AFa - Adfrontalpore; C - Clypeal seta; F - Frontal seta; Fa - Frontal pore; L - Lateral seta; La - Lateral pore; MD Dorsal seta on head; P - Posteriodorsal seta; $\mathrm{Pb}$ - Posterior pore; $\mathrm{S}$-Stemmatal seta; $\mathrm{Sa}$ and Sb - Stemmatal pores; SS - Substemmatal seta; SSa - Substemmatal pore

\section{References}

Adamski, D. and Brown, R.L. 1987. A new nearctic Glyphidocera with descriptions of all stages (Lepidoptera : Blastobasidae : Symmocinae). Proc. Entomol. Soc. Wash., 89(2): 329-343.

Allyson, S. 1980. Last instar larva of the gooseberry fruitworm, Zophodia convolutella (Lepidoptera : Pyralidae : Phycitinae). Ibid., 112: 43-45.

Allyson, S. 1981. Descriptions of last instar larvae of cabbage webworm Hellula rogetallis (Lepidoptera: Pyralidae) with a key to larva of North American species of Hellula. Ibid., 113(6): 361-364.

Allyson, S. 1981a. Last instar larvae of Pyraustini of America North of Mexico (Lepidoptera: Pyralidae). Ibid., 113: $463-518$.

Amutha, S. and David, B.V. 1998. Chaetotaxy of three Pyralid larvae on four Jasminum species. Ad. Bios. 17(1): 65-80.

Arita, Y. 1989. Records of two species of Phycodes Guenee (Lepidoptera : Brachodidae) from Thailand. Microlep. Thai., 2: 15-21.

Arita, Y. and Diakonoff, A. 1979. A survey of the Japanese species of Anthophila Haworth and Eutromula Froelich and their early stages (Lepidoptera, Choreutidae), with an appendix. Zoologische Verhandelingen, 166: 1-42.

Arthur, A.P. and Powell, Y.M. 1990. Description of the last-instar larva of Cochylis arthuri Dang (Lepidoptera: Cochylidae) and charactrs for separating it from last-instar larva of Cochylis hospes Walsingham. Can. Ent., 122: 627-631.

Azam, K.M. and Ali, M.H. 1965. Morphology of larvae of Dichocrosis punctiferalis Guenée, the caster shoot of capsule borer with special reference to its chaeetotaxy (Lepidoptera: Pyralidae). Indian J. Ent., 27: 423-431.

Bhattacherjee, N. S. and Menon, M.G.R. 1962. External structure of the various stages of Hymenia recurvalis (Fabricius) (Pyralidae: Lepidoptera). Ibid., 24: 252-263.

Center, T. D., Balciunas, J.K. and Habeck, D.H. 1982. Descriptions of Sameodes albiguttalis (Lepidoptera: Pyralidae) life stages with key to Lepidoptera larva on Waterhyacinth. Ann. Ent. Soc. Am., 75: 471-479. 
Common, I.F.B. 1973. A new species of Tracholena (Lepidoptera, Tortricidae) attacking Klinkii pine in Papua New Guinea, with a description of the larva and pupa of T. Homopolia from Australia. J. Aust. Ent. Soc., 12: 301-306.

Darling, D.C. 2003. Morphology and behavior of the larva of Calindoea trifascialis (Lepidoptera: Thyrididae), a chemically defended retreat-building caterpillar from Vietnam. Zootaxa, 225: 1-16.

Davis, D.R. 2000. Brachygyna incae, a new genus and species of Psychid from Peru with a typical larval biology (Lepidoptera: Psychidae). Trop. Lepid., 10(2): 51-58.

Doerksen, G.P. and Neunzig, H.H. 1975. Description of some immatures Nephopterix in the Eastern United States (Lepidoptera: Pyralidae: Phycitinae). Ann. Ent. Soc. Am., 68(4): 623-639.

Evans, D. 1962. Descriptions and life history of Melanolophia imitata (Walker) (Lepidoptera: Geometridae). Can. Ent. 94: 594-605.

Franzmann, B.A. and Garrett, R. 1978. Description of the immature stages and adult genitalia of the banana scab moth, Nacoleia octasema (Pyralidae: Pyraustinae), from North Queensland. Pacific Insects., 19(1-2): 45-51.

Godfrey, G.L. 1973. The larva of Platysenta albalabes (Grote) (Lepidoptera : Noctuidae). Proc. Ent. Soc. Wash., 75(2): $187-191$.

Goel, S.C. and Kumar, A. 1981. Cephalic demarcations and chaetotaxy of larval Diacrisia obliqua (Walker) (Arctiidae). Uttar Pradesh J. Zool., 1: 1-10.

Hashimoto, S. 1982. Immature stages of four Japanese Trichopterygini (Lepidoptera: Geometridae: Larentiinae). Tinea., 11(5): 99-112.

Hashimoto, S. 1986. Immature stages of Heterophleps fusca fusca (Butler) (Geometridae: Larentiinae). Tinea., 12(9): 81-84.

Hashimoto, S. 1991. The immature stages of Japanese species of the genus Episteira Warren (Lepidoptera: Geometridae). Nat. Hist. Res., 1(2): 59-64.

Hashimoto, S. 1991a. The immature stages of Carige Scutilimbata (Geometridae, Larentiinae). Tinea., 13(28): $107-111$.

Heinrich, C. 1916. On the taxonomic values of some larval characters in the Lepidoptera. Proc. Ent. Soc. Wash., 18: $154-164$.

Hinton, H.E. 1946. On the homology and nomenclature of the setae of lepidopterous larvae with some notes on the phylogeny of the Lepidoptera. Trans. R. Ent. Soc., Lond., 97: 1-37.

Horak, M. 1991. Morphology. pp. 1-22. In : Vander Geest, L.P.S. and Evenhuis, H.H. (Eds.) Tortricid pests, their biology, natural enemies and control. World Crop Pests 5, xviii+808pp. Amsterdam.

Itämies, J. and Kyrki, J. 1983. Biology and larva and Aproaerema karvoneni (Lepidoptera : Gelechiidae). Notulae Entomol., 63: 127-130.

Komai, F. and Ishikawa, K. 1987. Infestation of chestnut fruits in China with two species of the genus Cydia (Lepidoptera : Tortricidae). Jpn. J. Appl. Ent. Zool., 31: 55-62.

Leonard, J.G., Grehan, J.R.B and Parker, B.L. 1992. First instar description of Korscheltellus gracilis (Grote) and Sthenopis auratus (Grote) (Lepidoptera: Hepialidae) with a consideration of cladistic relationships between setae. J. New York Entomol. Soc. 100(4): 594-614.

Lin, C.S. 1995. Description of last-instar larvae of 31 species of Taiwan Spilomelini (Lepidoptera: Pyralidae: Pyraustinae). Bull. Nat. Museum Natural Sci., 6: 107-130.

Liu, Y. and Nasu, Y. 1993. A new tortricid moth attacking spruce in China (Lepidoptera). Tinea., 13(24): $245-251$.

Liu, Y. and Nasu, Y. 1993a. Two new species of tortricids attacking conifers in the northwest part of China (Lepidoptera). Tyo to Ga. 44(2): 60-67.

Mackay, M.R. 1972. The larva of Nomophila noctuella (Lepidoptera: Pyralidae). Ibid., 104: 1479-1481.

Mathur, R.N. 1954. Immature stages of Indian Lepidoptera No. 9 Pyralidae, subfamily Pyraustinae. Indian For. Rec., 8(11): $241-265$.

Mathur, R.N. 1959. Immature stages of Indian Lepidoptera No. 12. Pyralidae, subfamily Pyraustinae. Ibid., 9(10): $183-210$.

Mathur, R.N. and Singh, P. 1963. Immature stages of Indian Lepidoptera 13-Pyralidae, subfamily Pyraustinae. Ibid., 10(6): 117-148.

Mukherji, S. and Singh, H. 1951. Studies on the chaetotaxy of larvae of Plusia species (Lepidoptera: Phalaenidae). Proc. R. Ent. Soc. Lond., 20: 15-24.

Nasu, Y. 1995. Heleanna melanomocla (Meyrick) (Lepidoptera:Tortricidae), feeding on mangoin Taiwan. Trans. Lepido.Soc. Japan., 46(3): 159-164.

Nasu, Y. and Komai, F. 1997. A new species of genus Hendecaneura Walsingham (Lepidoptera, Tortricidae) injurious to the twigs of Hirado azalea Hybrids from Japan. Jpn. J. Ent., 65(2): 413-420.

Nasu, Y., Kawasaki, K. and Arakaki, N. 1993. Statherotis discana (Felder et Rogenhofer) (Lepidoptera : Tortricidae) injurious to Litchi from Japan. Appl. Entomol. Zool., 28(1): 97-101.

Neil, K.A. and Specht, H.B. 1987. Sixth instar larvae of Noctua pronuba (L.) (Lepidoptera: Noctuidae). Can. Ent., 119: $209-214$.

Ogunwolou, E.O. 1978. Sceliodes laisalis (Pyralidae): description of the mature larva and note on its feeding habit. J. Lepid. Soc., 32(8): 175-177.

Ogunwolu, E.O. and Habeck, D.H. 1979. Descriptions and keys to larvae and pupae of the grass loopers, Mocis spp., in Florida (Lepidoptera: Noctuidae). Fla Entomol., 62(4): 402-407.

Passoa, S. and Habeck, D.H. 1987. A description of the larva and pupa of Rupela albinella, a pest of rice in Latin America (Lepidoptera: Pyralidae: Schoenobiinae). Fla Entomol., 70(3): 368-375. 
Pinheiro, L. R., Silva, R. O. and Duarte, M. 2011. Immature stages of the moth Lobeza dentilinea (Lepidoptera : Noctuidae) with rediscription of the species based on male and female morphology. Zoologia (Curitiba)., 28(4): 517-524.

Rishi, N.D. 1971. Studies on the external morphology and chaetotaxy of ultimate instar larva of Agrotis ypsilon Rott. (Lepidoptera: Noctuidae), a serious agricultural pest in Kashmir. Kashmir Sci., 8(2): 143-156.

Rose, H.S. and Behl, N.K. 1985. Cephalic chaetotaxy of the last instar larva of a Pyralid: Corcyra cephalonica (Stainton) (Lepidodptera). Uttar Pradesh J. Zool., 5(2): 195-198.

Rose, H. S. and Singh, D. 2010. Cephalic chaetotaxy of the last instar larva of a pyralid: Syllepte derogata (Fabricius) (Lepidoptera). J. Threatened Taxa., 1(12): 672-673.

Singh, B. 1956. Some more Indian geometrid-larvae (Lepidoptera), with a note on the identity of components of various groups of setae. Ibid., 9(6): 131-163.

Sohi, G.S. and Mavi, G.S. 1969. Morphology and chaetotaxy of the larvae of Agrotis flammatra Schiff. (Noctuidae : Lepidoptera). Agric. J. Res., 6(1): 224-232.

Solis, M.A., Davis, D.R. and Nishida, K. 2005. Life history and systematics of Albusambia elaphoglossumae (Lepidoptera: Crambidae): A new genus and species of musitimine with leaf mining biology from Costa Rica. Rew. Biol. Trop., 53(3-4): 487-501.

Stehr, F.W. 1987. Immature insects. Kendall/Hunt Publishing Company, Iowa. pp 729.

Valley, K. and Wheeler, A.G. 1976. Biology and immature stages of Stomopteryx palpilineella (Lepidoptera : Gelechiidae), a leafminer and leaftier of Grownvetch. Ann. Ent. Soc. Am., 69(2): 317-324.

Wong, H.R. and Melvin, J.C.E. 1976. Biological observations and larval descriptions of Enargia decolor (Lepidoptera: Noctuidae) on trembling aspen in northern Alberta (Canada). Can. Ent., 108: 1213-1220.

Wong, H.R., Drovin, J.A. and Szlabey, D.L.1983. Identification of three species of Proteoteras (Lepidoptera : Tortricidae) attacking shoots of Manitoba maple in the Canadian Prairies. Ibid., 115: 333-339.

Yen, S.H., Solis, M.A. and Goolsby, J.A. 2004. A New Musotimine genus Austromusotima, (Lepidoptera: Crambidae) feeding on old world climbing fern, Lygodium microphyllum (Schizaeaceae). Ann. Ent. Soc. Am., 97(3): 397-410.

Yoshiyasu, Y. 1980. A systematic study of the genus Nymphicula Snellen from Japan (Lepidoptera: Pyralidae). Tyo to Ga. 31(1-2): 1-28.

Yoshiyasu, Y. and Ohara, K. 1982. A new Aphidophagous species of a Phycitine Genus Cryptoblabes from Japan (Lepidoptera: Pyralidae). Tyo ta Ga. 33(1-2): 51-60. 


\section{PLATE 1}

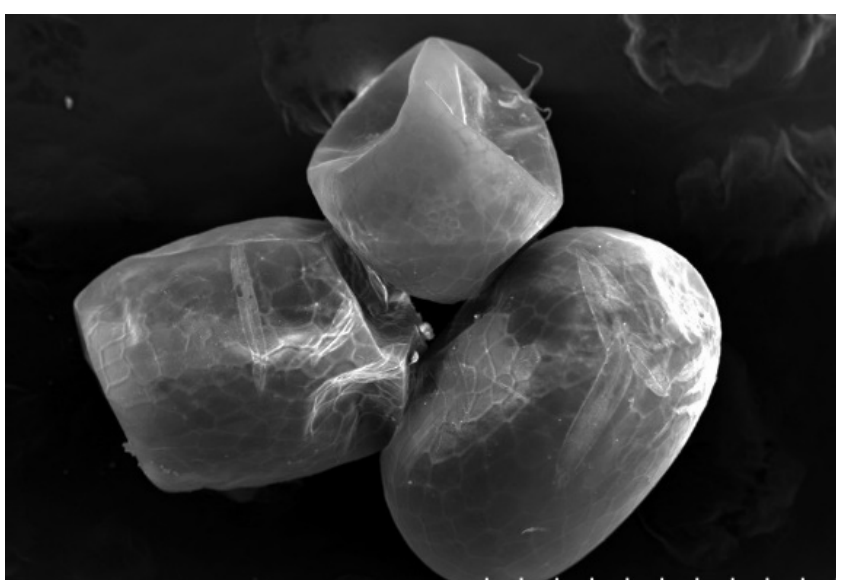

1. Egg

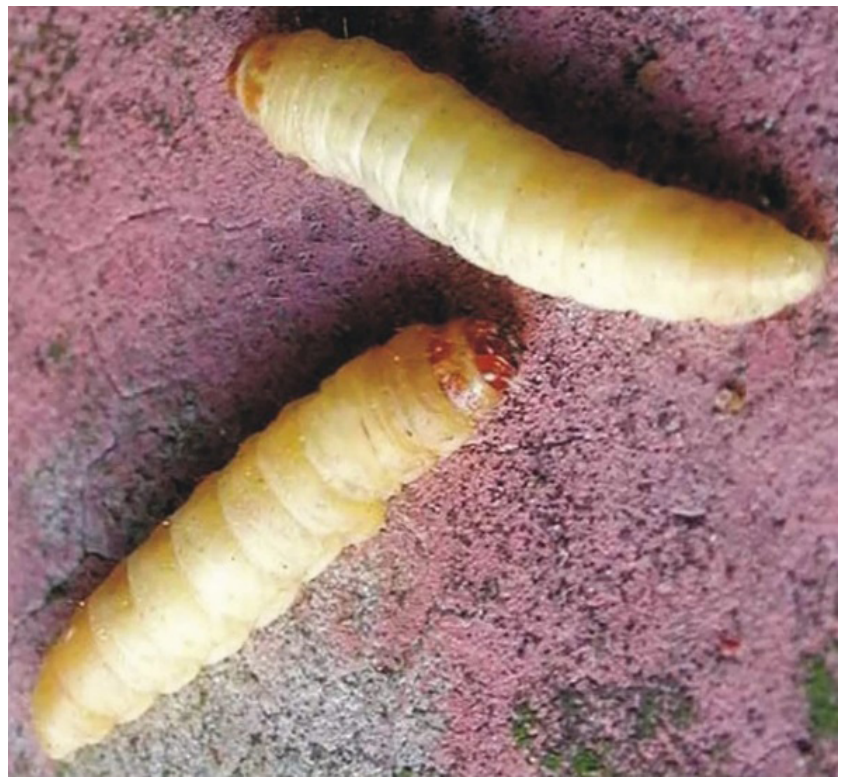

3. Larva

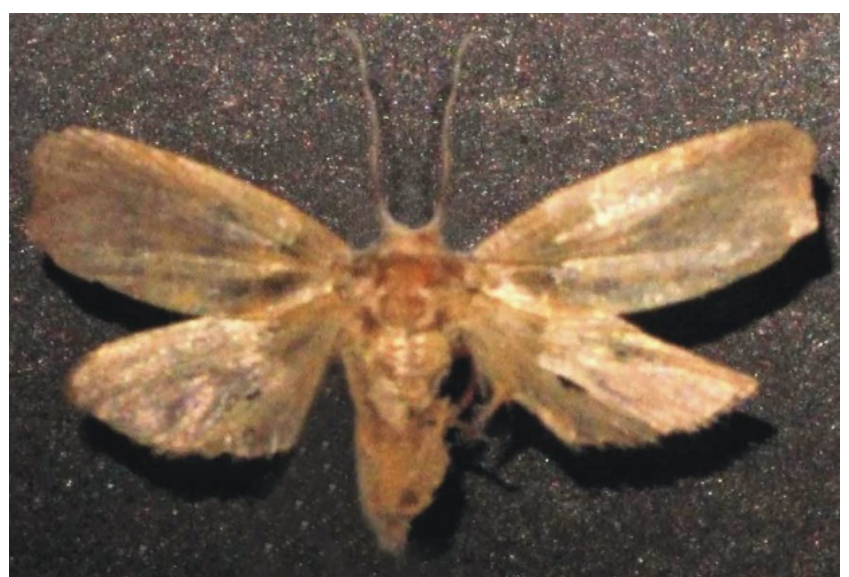

2. Adult

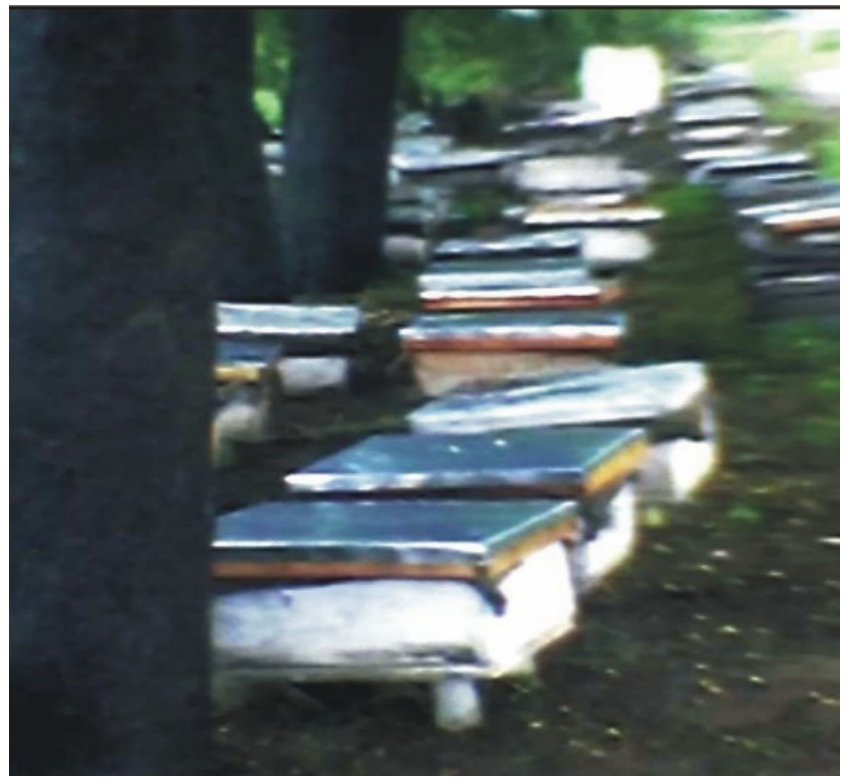

4. Infested beehives 


\section{PLATE 2}

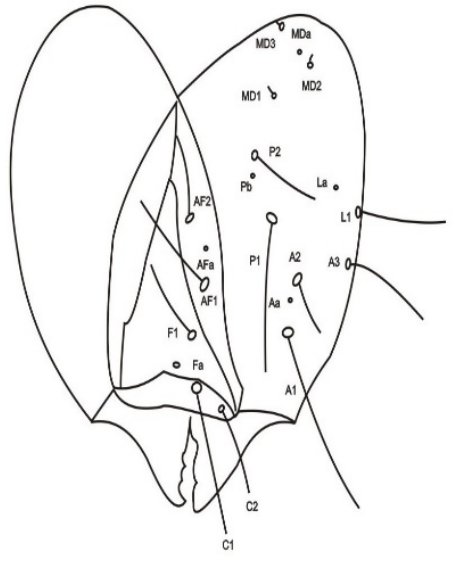

1

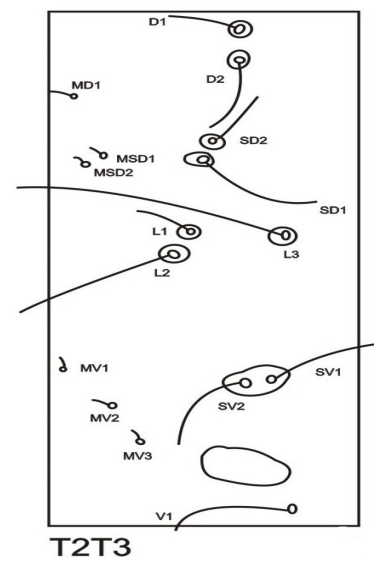

4

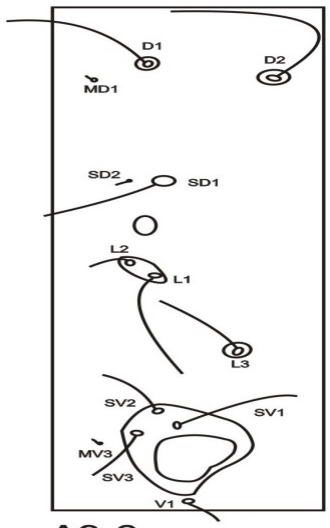

7

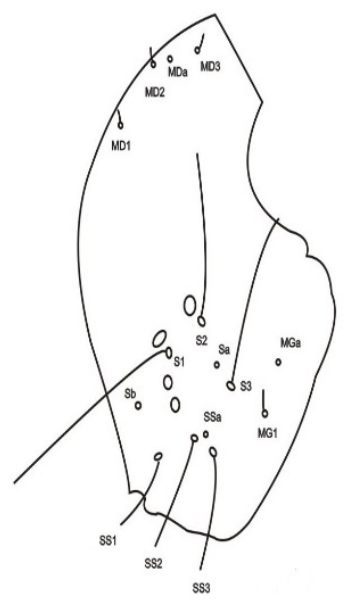

2

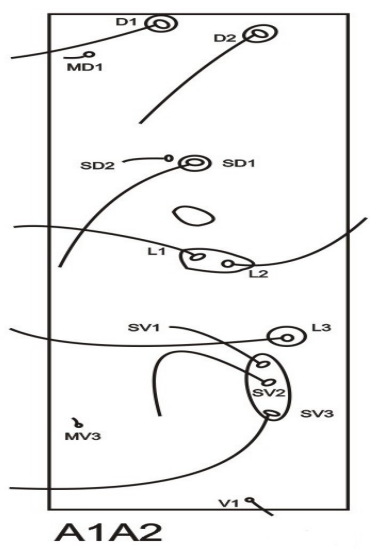

5

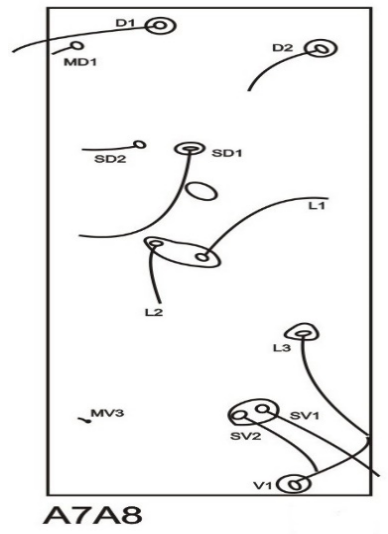

8

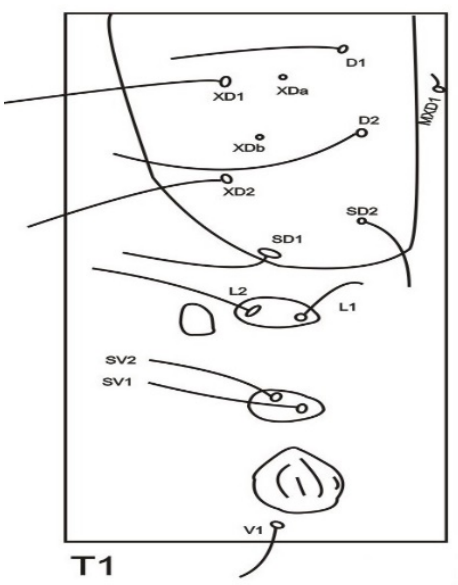

3

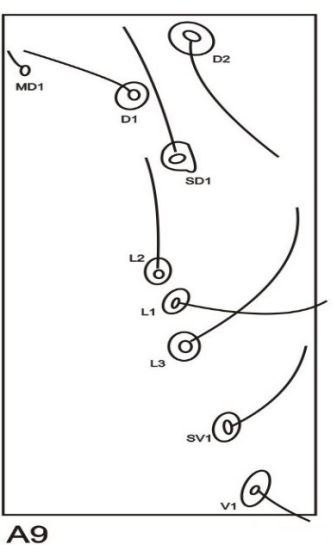

6

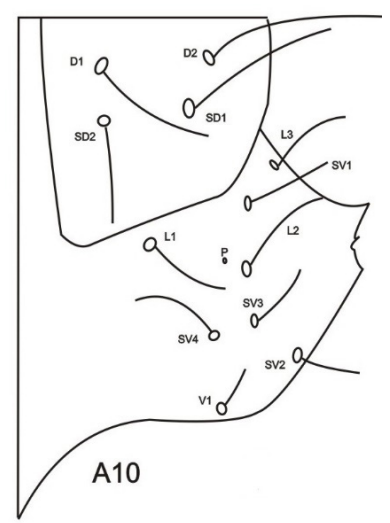

9

Setal maps of Galleria mellonella (Linnaeus) - Figure $1 \& 2$ Head-frontal and lateral view; Figure $3 \& 4$ shows setal maps of thoracic segments; Figure 6, 7, 8, 9 \&10 shows setal maps of different abdominal segments 